\title{
Archéopages
}

Archéopages Archéologie et société

43 | 2016

Médecines

\section{Un steak de cheval pour Néandertal}

David Hérisson

\section{OpenEdition}

Journals

Édition électronique

URL : https://journals.openedition.org/archeopages/905

DOI : 10.4000/archeopages.905

ISSN : 2269-9872

\section{Éditeur}

INRAP - Institut national de recherches archéologiques préventives

\section{Édition imprimée}

Date de publication : 1 novembre 2016

Pagination : 104-105

ISSN : 1622-8545

\section{Référence électronique}

David Hérisson, « Un steak de cheval pour Néandertal », Archéopages [En ligne], 43 | 2016, mis en ligne le 01 décembre 2018, consulté le 09 juin 2021. URL : http://journals.openedition.org/archeopages/905 ; DOI : https://doi.org/10.4000/archeopages.905

Ce document a été généré automatiquement le 9 juin 2021.

(c) Inrap 


\title{
Un steak de cheval pour Néandertal
}

\author{
David Hérisson
}

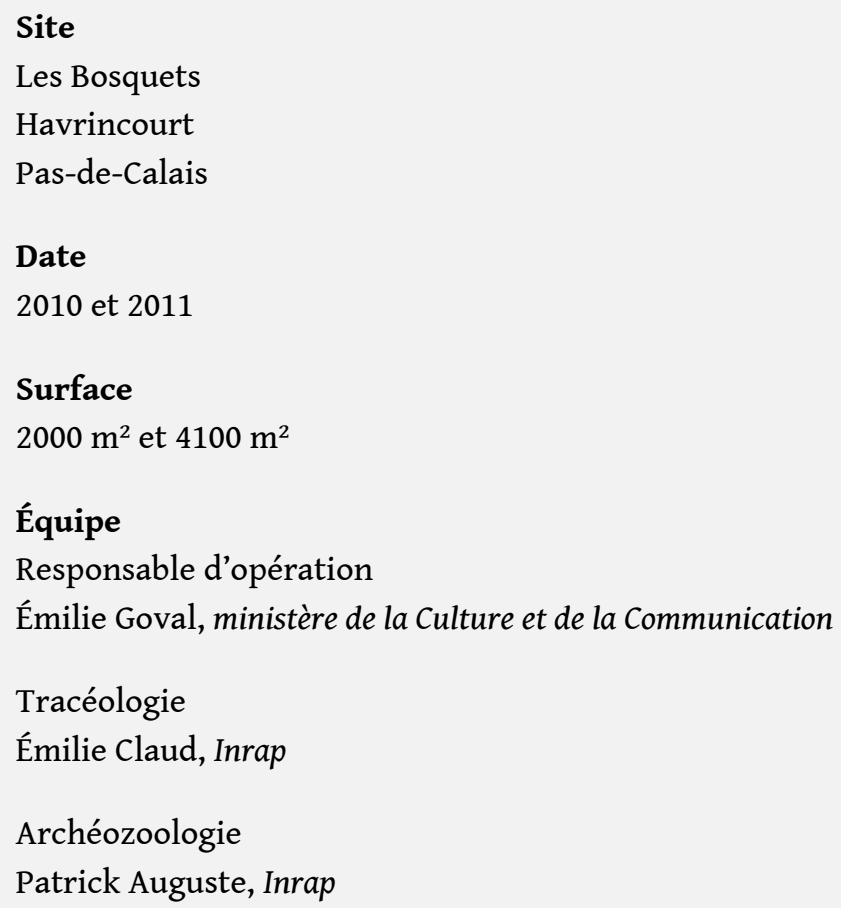

Néandertal n'était pas uniquement charognard mais un redoutable chasseur. Physiquement apte à la chasse et fin connaisseur de son environnement, il est désormais considéré par les chercheurs comme l'un des plus grands chasseurs de tous les temps. Ce statut renouvelé est le fruit des avancées récentes et nombreuses de la recherche. Ces dernières ont permis de faire tomber un à un les multiples préjugés concernant son mode de vie, son régime alimentaire ou encore sa capacité d'adaptation à certains milieux et certaines conditions climatiques. Dans ce courant, les analyses menées sur le site d'Havrincourt, fouillé en 2010 et 2011, ont été l'occasion d'apporter de nouveaux éléments de réflexion sur la manière dont Néandertal chassait et exploitait son territoire. 
2 Les fouilles préventives menées sur la commune d'Havrincourt dans le cadre du projet du canal Seine-Nord Europe ont mis au jour quatre niveaux d'occupation échelonnés du Paléolithique moyen au Paléolithique supérieur (Goval, Hérisson, 2012; Goval et al., 2012; Antoine et al., 2014). Au sein de cette succession, le niveau Hav.1-N3, daté d'environ 70000 ans, a livré des éléments riches d'enseignement.

Sur les $2000 \mathrm{~m}^{2}$ fouillés, seuls huit éclats Levallois étaient associés à des restes fauniques. Ces éclats, remarquables par leurs grandes dimensions (d'une longueur supérieure à $10 \mathrm{~cm}$ ), ont été importés sur le site. Ils proviennent certainement d'ateliers de production à l'image du site d'Hermies (Vallin et al., 2006), situés dans la vallée, à proximité immédiate des blocs de matière première. Les éclats de haute facture ont été soigneusement préparés par de nombreux enlèvements centripètes et par un facettage attentionné [ill. 1 et 2]. Le détachement des éclats s'effectue au percuteur dur en percussion rentrante comme l'atteste la proéminence des bulbes et les stigmates de percussion. Le soin porté à la préparation des éclats permet d'obtenir des produits standardisés, symétriques selon le plus grand axe, aux tranchants des bords droits et gauches similaires. Élément rare, une morphologie similaire de la base des éclats a attiré notre attention.

\section{Havrincourt - secteur $1-N 3$, éclat Levallois préférentiel de grandes dimensions $(15 \times 8,5 x$} $1,6 \mathrm{~cm})$.

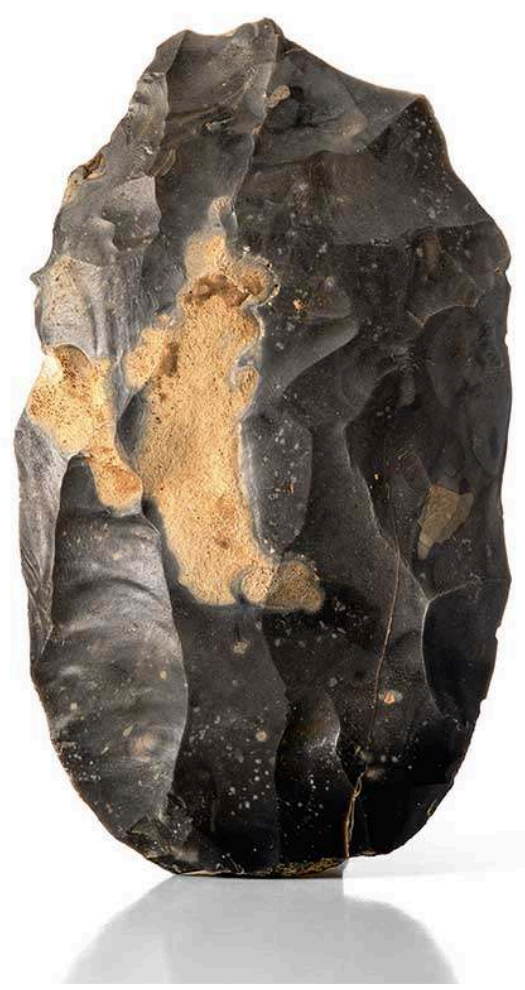


2. Havrincourt - secteur $1-N 3$, localisation et photographie des petits esquillements discontinus liés à la coupe de matière tendre à mi dure (boucherie). La mesure de l'angle de coupant correspond à une moyenne des angles mesurés le long de la zone active.

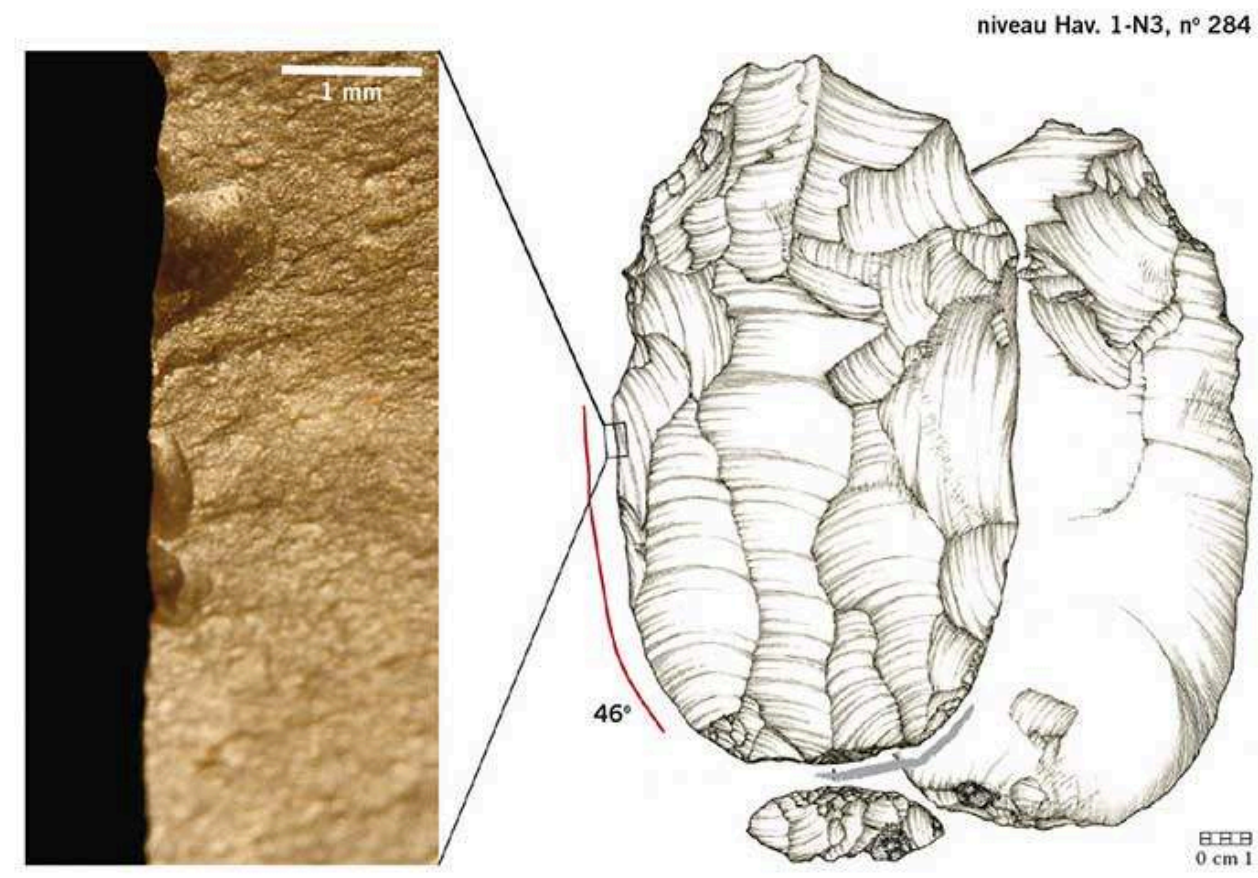

(c) E. Claud/Inrap

4 En poursuivant les investigations, il a été remarqué que tous les éclats Levallois présentaient sur l'un de leurs bords une zone de petites retouches marginales à proximité du talon [voir ill. p. 102-103]. Ses dimensions sont toujours comprises entre 15 et $25 \mathrm{~mm}$. Afin de saisir le mode de fonctionnement des éclats et le rôle que joue cette zone de retouche, une étude tracéologique a été menée concernant les éventuelles traces d'usure conservées sur leur tranchant et sur leur surface. Le recours à la loupe binoculaire (faible grossissement, de 10 à 30x) renseigne principalement sur le mouvement effectué et la dureté de la matière travaillée, le microscope métallographique (fort grossissement, de 100 à 500x) permet de rechercher la nature précise de la matière travaillée (viande, peau fraîche ou sèche, bois, os, etc.), ainsi que le mouvement. Au terme de l'étude, trois éclats présentent des traces d'utilisation résultant d'activité de découpe en boucherie [ill. 2 et 3]. Deux autres éclats auraient été utilisés, l'un pour couper une matière tendre comme de la peau ou de la viande et l'autre, pour percuter des matières dures organiques. C'est donc au traitement de carcasses animales qu'ont servi les éclats Levallois d'Havrincourt. 
3. Illustration de l'utilisation et du mode de préhension supposé des éclats Levallois préférentiels d'Havrincourt, bulbe dirigé vers le haut.

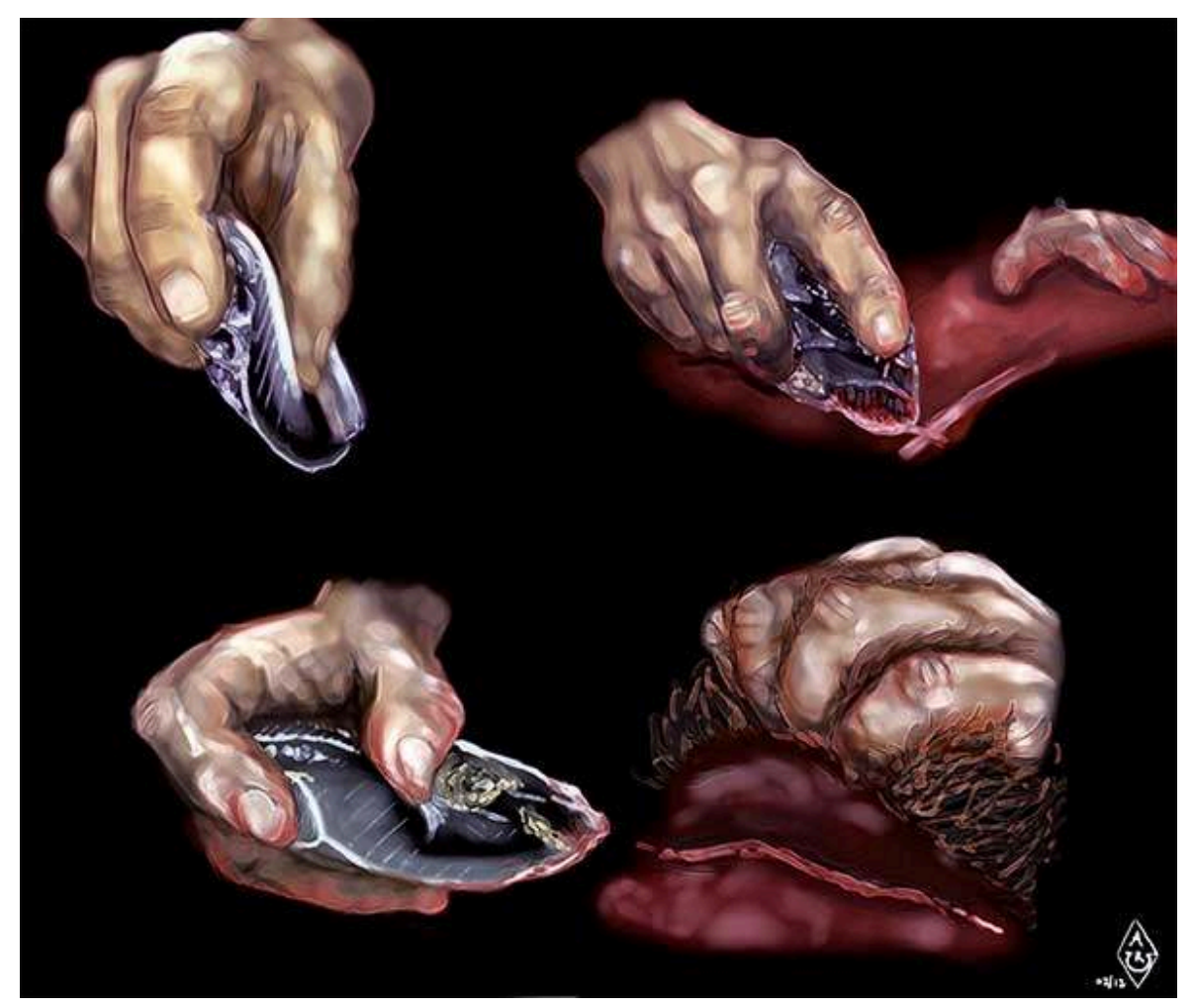

(C) C. Font/Inrap

5 Sur l'aire de fouille, seize restes de grands herbivores ont été retrouvés. Le rhinocéros laineux (Coelodonta antiquitatis) est représenté par deux os (un métatarsien et un tibia droit) appartenant probablement au même individu, dont la présence semble sans lien évident avec les éclats. Cependant, la majorité des restes fauniques, treize dents de cheval, sont localisés à proximité immédiate de deux éclats Levallois. Ces dents sont les seuls témoins ayant survécu à l'acidité du sol, mais d'autres restes de carcasse de cheval devaient joncher le sol au moment de l'abandon du site par Néandertal. La tracéologie a également mis en évidence que la base des éclats et la retouche adjacente au talon sont des aménagements qui permettaient une bonne préhension de la pièce pour s'en servir en tant que couteau [ill. 3].

6 L'ensemble de ces données permettent de reconstituer pour le niveau Hav.1-N3 un moment de vie d'un groupe de Néandertaliens il y a 70000 ans. Munis d'éclats Levallois de grandes dimensions produits dans la vallée, ils sont venus chasser des chevaux dans la plaine steppique d'Havrincourt. Après avoir découpé des carcasses de chevaux, ils repartent du site en abandonnant sur place une partie de leurs couteaux de boucherie. Des quartiers de viande prélevés annoncent un festin, un steak de cheval pour Néandertal. 


\section{BIBLIOGRAPHIE}

ANTOINE P., GOVAL É., JAMET G., COUTARD S., MOINE O., HÉRISSON D., AUGUSTE P., GUÉRIN G., LAGROIX F., SCHMIDT E., ROBERT V., DEBENHAM N., MESZNER S. et BAHAIN J.-J., 2014, « Les séquences loessiques Pléistocène supérieur d'Havrincourt (Pas-de-Calais, France) : stratigraphie, paléoenvironnements, géochronologie et occupations paléolithiques ", Quaternaire, vol. 25/4, p. 321-368. http:// quaternaire.revues.org/7278; DOI : 10.4000/quaternaire.7278

GOVAL É., HÉRISSON D., 2012, « Découverte inédite de trois occupations du Pléniglaciaire moyen du Weichselien à Havrincourt "Les Bosquets" (Pas-de-Calais, France) », Bulletin de la Société préhistorique française, t. 109, $\mathrm{n}^{\circ}$ 2, p. 342-345. www.persee.fr/doc/ bspf_0249-7638_2012_num_109_2_14117; DOI : 10.3406/bspf.2012.14117

GOVAL É., HÉRISSON D., LOCHT J.-L., COUTARD S., ANTOINE P., CLAUD É., 2012, « Hunting camp at the end of the Middle Paleolithic at Havrincourt "Les Bosquets" (Pas-de-Calais, France) », in conARD N. J., DELAGNES A. (éd.), Settlement dynamics of the Middle Paleolithic and Middle Stone Age, vol. 4, Tübingen, Kerns Verlag, p. 311-328.

VALLIN L., MASSON B., CASPAR J.-P., DEPIEREUX É., 2006, « L'outil idéal. Analyse du standard Levallois des sites moustériens d'Hermies (Nord de la France) », Paléo, Revue d'archéologique préhistorique, 18, p. 237-272. http://paleo.revues.org/347

\section{INDEX}

Index chronologique : Paléolithique moyen

\section{AUTEUR}

DAVID HÉRISSON

Inrap, UMR 7194 « Histoire naturelle de l'homme préhistorique » responsable de secteur 